\title{
Towards a social sustainability in higher education: enhancing students' solidarity and togetherness through collaborative projects in racially diverse learning environments
}

JRAMOHAI ${ }^{1}$

\begin{abstract}
One key goal in the mission and vision statement of the University of the Free State is to recruit the best and most diverse students who work in solidarity and togetherness across social and historical divides. This goal is further echoed in the academic divisions' own mission and vision statements which endeavour to ensure that the broader institutional goals are met. The Faculty of Education in this institution for instance, in accordance with the institution's vision, has included in their vision statement issues of diversity and social transformation which foreground the Faculty's commitment to produce teachers who show solidarity in their dealings with others. A question that is worth considering though is how these mission and vision statements can be implemented in practice by lecturers in their classes. In this paper I report on an action research project towards the realisation of the vision of togetherness and solidarity of the University of the Free State and the Faculty of Education, in which spaces are created for collaborative work for Honours classes. The results from this classroom practice indicate that students' solidarity and togetherness in racially diverse learning environments can be enhanced through collaborative students' work designed by lecturers.
\end{abstract}

Key words: sustainability, higher education, diversity, solidarity, togetherness

\section{Introduction}

Across the globe, higher education institutions (HEIs) take it as their human project to create spaces that are welcoming for all within their institutions (Milem, Chang and Antonio, 2005: 23). These spaces are driven by policies and practices that take into consideration issues of diversity in the provision of services for students and in organisational learning. According to Milem et al. (2005: iv), welcoming environments focus on students' intellectual and social development and pay attention to the enhancing nature of the cultural differences that learners bring to the educational experience. It is in such environments that difference is not regarded as a negative phenomenon but as an element that contributes to the pedagogical success of students from different social, economic and ethnic backgrounds. Through student and staff collaboration towards the advancement of quality education, institutions around the globe work hard to bring these parties together in an effective pedagogical practice (Balasooriya, Di Corpo and Hawkins, 2010: 3). According to the Literacy and Numeracy Secretariat (2010: 3-4) collaborative pedagogical practices are iterative approaches in which teachers and students engage as they reflect and build on their experiences. Through these, both teachers and students create diversity, broaden their thinking and ask complex questions that tap into their inner selves. At times though, institutions are challenged to create

1 Juliet Ramohai $(\mathrm{PhD})$ is a Lecturer of Psychology of Education in the School of Education Studies,Faculty of Education at the University of the Free State. Her research foucuses on issue of race, gender and social justice. Email: ramohaij@ufs.ac.za

TD The Journal for Transdisciplinary Research in Southern Africa, 9(3), Special edition, December 2013, pp. 430445. 
environments where diversity thrives and where social spaces reflect the sustainability of upholding the institutions' pledges to create inviting and welcoming spaces.

Particularly in the context of South Africa, the legacy of the previous political dispensation seems to have had a bearing on the sustainability of the attempts by institutions to create environments where every constituent feels a sense of belonging. The South African education system before 1994 was marked by exclusions, racial segregations and racial stereotypes that clustered South African higher education constituencies into socially and intellectually unequal race groups (Waghid, 2002: 458; Bunting, 2006: 39). This higher education system was such that HEIs, such as universities and technikons were cast in a racial mould (Carrim, 1998: 13). There were HEIs for white students and staff only, as well as those only for black people who were categorised into African, Indian and Coloured. The ideology behind this division was that of superiority and inferiority (DoE 2008: 9). White people were believed to be knowledge creators at their universities and managers in the application of this knowledge in their technikons (Bunting, 2006: 40). On the other hand, the education offered at black universities was engineered to be suitable for graduates to serve as assistants to white people and to teach a curriculum that was believed by the apartheid masters to be adequate for black learners (Engelbrecht, 2006: 7). Engelbrecht (ibid) argues that this perception of black people being intellectually inferior constituted misconceptions by their counterparts that black people could not perform academically. It was from these perceptions and divisions that both black and white groups of students and learners held intelligence stereotypes against each other.

The determination by the government to redress the past divisions is clearly documented in the Department of Education's White Paper 3 (1997) in which issues of equity and equality are stressed. The mergers of former white (and mostly Afrikaans) HEIs with other perceived less worthy institutions were considered a strategy that would ensure that the racial divisions in South African higher education were eradicated and equity practised by the institutions. This, together with most of the institutions' vision and mission statements provides hope of institutional spaces that are characterised by unity and togetherness. However, the stereotypical belief of low intellectual ability on the part of black people could have led them to feel inferior, undervalued and alienated, and may still influence how they value themselves and act within the now merged institutions (Mabokela, 2007: 176; Osa, 2007: 2). It seems as if the past divisions that were experienced in and characterised South African HEIs continue to impact on the activities both staff and students experience in the new higher education landscape (Ramohai, 2013: 30).

\section{Rationale and statement of the problem}

Institutions around the globe and in South Africa, through their practices and programmes, have similar interests in creating spaces that are welcoming for all and that provide all constituencies with a sense of belonging and solidarity (DoE, 1997; Hrabowski, 2011: 3; Milem, 2005: vi). The success of such projects and programmes lies mostly in how much constituencies in the institutions embrace the goals of such projects, and are willing to contribute meaningfully to the success of the goals set therein. They should endeavour to create spaces where diversity thrives and students feel welcome. At the University of the Free State (UFS) there is a project termed 'the human project'. Among other important issues, this project aims at assisting students to accept and respect themselves and others, which can 
be seen by their willingness to put aside their social differences and work together towards their own academic and social success. ${ }^{2}$

However, given its history of exclusion, discrimination and racism, within the South African higher education context and the UFS specifically, the task to realise the goals of the human project is challenging. The continued racial tensions in mostly historically white SAHEIs (DoE, 2008) present a real challenge for institutions to create a socio-habitat in which all members work together in harmony and as a unit; an environment in which both staff and students learn to embrace diversity and cooperate (Ramohai, 2013: 60).

Since I joined the UFS, as a Black female lecturer, I have observed that it is a challenge to get black and white students to work together. I believe that the major aspect that has led to this division is language (where one group has learnt in English and the other in Afrikaans). Students have the option to enrol for classes in either Afrikaans or in English, and these two groups do not share physical spaces in classrooms. In my opinion, this contributes to the 'othering' that students seemed to have adopted. As true as it could be that the UFS, through a student diversity course which every first year student is required to enrol in, is creating an opportunity for this togetherness and the Faculty of Education through its diversity programme for the first years is doing the same, the parallel medium of instruction is in my opinion still counterproductive to these good initiatives. Through this language division in classrooms, the students are not afforded a chance to get to know and understand one another by sharing experiences and knowledge in the same spaces but learn in segregated spaces while they are considered to be students within the same programmes and at the same institution.

However, in the Faculty of Education a decision was taken that from 2011 Honours classes would no longer be segregated. Students in the same courses would be instructed in one lecture room, with one language being used by the lecturer (Afrikaans or English), while interpreting services would be used to translate to the other language for those students who do not understand. This initiative could be regarded as the Faculty's endeavour to work closely with the vision of togetherness and oneness that the Faculty and the UFS have set (while also solving other practical problems).

In spite of this, although this could be seen as a positive move to ensure togetherness, as a lecturer in these classes, I have noticed that the segregation of the students has persisted even when they share the same classroom space. White students come and sit at one end of the classroom and the black students at the other end. During classroom discussions, my experience is that the black students often do not participate and the white students usually monopolise the discussions. Even in instances where a student comes late to class, the student will look for a space next to those of the same race. When I have tried, at times, to get the black students engaged, they are very reluctant to take part in discussions. I have been bothered by this behaviour for a long time and even thought that perhaps I am responsible for creating an unwelcoming environment for the students and have to find a way to overcome this barrier. The question that I thus posed was: How could I change my own practice and that of my students to create an atmosphere of oneness in my class where all students feel comfortable about sitting close to one another and participating in discussions without feeling inbibited?

2. See, UFS, University of the Free State website at http://www.ufs.ac.za/content.aspx?id=12 


\section{Research methodology}

I thus embarked on an action research study to explore the challenges that impede and frustrate the institutions' endeavours to create an environment in which students from diverse racial backgrounds can work together in harmony and overcome these challenges. I explored how my classroom environment as exemplified through the classroom practice I undertook contributed towards the realisation of the aspirations to create unity and togetherness in the students at the UFS. My attempts to create such spaces is reported in this paper to encourage and present a challenge to other classroom practitioners to come up with ways in which they can also advance the creation of socially sustainable higher education institutions.

The action research process (cf. Cresswell, 2010: 28, McNiff and Whitehead, 2010: 11) for this study started with problem identification in which I used my own observation (as reported in the problem statement) as a lecturer to identify areas of concern in my Honours classes. I should point out here that my observations in my classes were rooted in my own disposition as a black academic within a historically white institution that was undergoing dramatic transformation. Eagle, Hayes and Sibanda (2006: 506) caution that the researcher who engages in action oriented research should acknowledge their role and biases within their research roles. I should therefore point out that experiences of my own perceptions with regard to what on my side seemed like exclusive practices towards me as a black woman academic by my colleagues had made me sensitive to any form of situation that posed a threat for divisions among my students and my quest to challenge such systems made me aware of the lingering possibility for division among my students. I however tried not to impose this disposition on the progress of the classroom exercise that we engaged in as a class by viewing my students as a unit and not as entities of race. So, although my reporting will seem like I am pitting black students from white students, this was not done with the aim of highlighting weaknesses in any one of the groups, but to tackle the issue in hand, which was to assist my students to challenge their divisive views towards each other and to begin to work together beyond race. Also, being a black woman in South Africa, a country that was plagued by incidences of divisions among its people and the discrimination of black people, I could have interpreted my classroom situation, which to some people could have been a harmless situation, through the lenses of a black person that is sensitive to issues of race. It therefore needs to be understood that I approached this exercise from my standpoint as explained. Standpoint approaches could be criticised as lacking credibility (Eagle et.al. 2006), but as Harding (1993: 51) points out, any research exercise can never be free from bias as all researchers carry their values into the research. My observations aided the discovery of how interpersonal relationships played out among students. Drawing from Kawulich's (2005, nd) study on the importance of participant observation as an important aspect of reflective studies, I used the participant observer approach, in which I was a part of my students' academic and classroom social life and worked with them to scaffold their experiences.

The observations were followed by informal interviews with a few of the students (both black and white). After each informal interview, I recorded the conversation in my journal which I had kept specifically for this purpose. Given (2008: 68, 522) defines informal interviews as casual conversations in which the researcher aims to discover how people conceptualise their environment and organise it into meaningful categories. In this case, students were involved in an exercise that would probe their critical thinking on matters of unity. 
Theoretical underpinning

My attempt at improving my practice and that of my students departs from the philosophical underpinning of Vygotsky's social constructivism (Hall, 2007: 96). Basing my teaching practice on the aspects of scaffolding and collaboration, which are enshrined in social constructivism, I believe that students' collaborative work can assist in scaffolding both their academic and social experiences. This could mean that as students work together, they can enhance their learning of the course content, while at the same time, are able to understand one another's beliefs, values and attitudes. These social aspects are very important in an educational environment. If students understand other people's beliefs and values, they can form learning communities that respect diversity and difference and that work towards the achievement of their goals. Knowledge of such diversity contributes to the rich array of learning experiences that individuals bring to the education environment.

Within the collaborative exercise, particular focus was given to how my students and I challenged the issues of marginalisation of each other's experiences and knowledge and also how we could fall into the trap of problematising other's social identities. The two concepts, marginalisation and problematisation, were drawn from Essed (1991:208) and Harding (1993: 51), who both have a strong inclination towards standpoint positions and strongly believe that marginalisation and problematisation divide people in racially diverse context. Marginalisation and problematisation according to Essed (ibid) suggest that people who are seen as racially and ethnically different are stereotyped as less intelligent, linguistically deficient, and lack social skills. This is the reason why those that consider themselves possessing stronger qualities than the others often exclude and discriminate against those that they believe to be weaker (even if subconsciously). In such cases, those that are discriminated against fail to function optimally and at times end up internalising such stereotypes and unconsciously act to confirm them. Such social dynamics could play themselves in any sphere of human interaction and it was my aim with the classroom practice reported in this paper, to explore if such processes could also be playing themselves out in the situation which I interpreted as problematic in my classroom. Through scaffolding within the ambit of these two processes, I believed that learners could get to understand each other's identities and challenge any stereotypes that they could have about themselves and each other. These two processes formed an analytical frame in the analysis of information collected.

\section{Participants}

I engaged my Educational Needs Honours class in collaborative exercises with the purpose of enhancing togetherness amongst them. This class consisted of 23 members; 13 white students and 12 black students. The collaborative exercises that I gave to my students required them to compile researched information on barriers to learning in an education setting. Among the factors that formed part of the reading material were racial issues as a barrier to learning. I chose this class as it seemed the most suitable because the module that they were doing dealt with issues of inclusion in education. As a result, this group was in a better position to understand the factors that would impact on the unity of learners in class, of which race could be one of them. As Inclusive education students, this group would further need to understand that they were going to work with diverse learners in schools and therefore needed to equip themselves with the skills that would prepare them for the realities of diversity in the school classroom. I saw the collaborative exercises as a way of exposing my 
students to the realities of the world of work in which they would experience diverse communities.

\section{Findings}

As stated earlier, the action research exercise reported in this study followed a cyclic approach. It involved a cycle of planning, taking action, reflecting on and evaluating the action taken to improve our practice; then starting all over again with a new plan where the previous one seemed not to have yielded the required results. During the problem identification phase, I approached some of the learners informally, in conversations and asked them why they seemed to be withdrawing from one another in class. I spoke to the students in groups and individually. These steps that I took aligned with the general way in which action research is conducted, where central issues of problem identification, planning, taking action, and reflections and evaluation are central to ensuring the success of the action research project (Mcniff and Whitehead, 2010: 26). Below I report on the results of my observations and the informal interviews that I conducted with my students.

\section{Problem identification}

There were a number of issues that students raised during the discussions I had with them. The major problem that seemed to characterise students' perceptions and beliefs about one another was race. They seemed to have slotted each other into groups of white and black and as a result, based their judgement on their internalised thoughts about each other. This clustering and slotting is according to Essed (1991: 204) a result of the social and political socialisation that individuals get from their communities and societies. Looking at the past SAHE landscape as depicted earlier (see introduction), the past political dispensation still had a bearing on how the students viewed themselves and the 'other' in the lecture room. This was apparent in their responses during my conversations with them as individuals and groups. Of the issues that they raised, they highlighted feelings of non-acceptance from their peers, a negative evaluation of self when in a biracial group and issues concerning the different languages of instruction to which students are exposed at the UFS. These issues are discussed below.

\section{Perceptions of uninviting attitudes from white classmates}

This point was raised mainly by the black students who claimed that they had tried in some classes to sit next to their white counterparts. They reported that their white classmates seemed uncomfortable when sitting next to them. This became evident when white students would immediately change seats if a black student came to sit next to them. In one conversation that I had with the black students regarding separate sitting, this is the response that I received:

\section{Ma'am, it is so difficult to sit next to those people. They make you feel so unwelcome. You will not understand this ma'am, but sometimes they practically stand to sit somewhere else if you try to sit where they are. Haven't you noticed that they sit alone together in class? We talk about it all the time with my colleagues and we think that they have a feeling that we are not as clever as they are...}


This complaint about exclusions in the sitting arrangement basically came from the black students. I could not help but wonder why the white students did not raise the same issue. Could it be that they were not bothered by the sitting arrangement and perhaps did not notice the negative message that it conveyed to their classmates? Essed (1991: 205) points out that some of these excluding behaviours are normalised within communities and the perpetrators never get to understand the effects of their behaviours on others. She further argues that, in racially diverse communities, race itself as a social construct, influences ingroup favouritism and out-group exclusions. This could have been the reason that my students, perhaps unconsciously preferred to form a sitting arrangement with those that they felt uncomfortable with. The problem with this in class though could be the resulting stereotypes that students could end up forming about one another in different groups. In the quote from the student above, the stereotype regarding intelligence could already be felt in the last line of her response, 'we think they have a feeling that we are not as clever as they are.' Tatum (2003: 60,61), in her book Why do all black students sit alone in the cafeteria, argues that it is these kind of thoughts, in which black students feel alienated, that bring them closer together in one group, forming an in-group that pushes any out-group members out; since these do not share a similar identity with the in-group members.

Perceptions and evaluation of self

From my own interpretative analysis of the conversations that I had with the black students, I noticed that they perceived themselves not on par with their classmates with regard to efficiency during class discussions and overall performance and understanding of concepts. They pointed to this as a reason for them not participating in discussions for fear of getting answers wrong and humiliating themselves. Responses like, 'ma'am, I just feel uncomfortable to respond in class, these people know so much they make you feel like you don't know anything' and 'I don't feel comfortable ma'am. Those ladies (white students) know most of this inclusive education stuff. Us in Lesotho we don't have inclusive education. What if I get an answer wrong and they laugh at me. But I will try to take part ma'am.' These and other responses indicated that the black students regarded the white students' willingness to engage in classroom discussions and to ask challenging questions as a sign of intelligence, while themselves were not since they did not have enough experience of the South African inclusive education context. Consequently, this led the black students (especially those from Lesotho) to feel that the context knowledge that those from South Africa had, gave them the upper hand in the discussions, as they would draw from their own school experiences. The only two South African black students that I had in my class, did not have a problem with understanding inclusion, but they however mentioned that they felt intimidated by the fluent way in which the white students expressed themselves. As a result of this, they also did not participate much in the class discussions.

While the above concern from the black students regarding their lack of sufficient detail in issues of inclusive education in South Africa could be justified, and while it could be understandable that this exerted a lot of pressure on the image of the black students and influenced their participation in class, I was concerned about the disabling impact this could have on them. They seemed to have resorted to forming their own comfortable spaces where they had convinced one another not to engage in classroom discussion and also had formed a space where they sat in a cluster in one part of the class. According to Daniel (2009: 4) this behaviour is a common defence mechanism in people who feel threatened by a social space, in which they feel excluded and ignored; they feel they do not have enough worthy knowledge 
capital to share with others. Although this kind of resistance mechanism is not created outside the classroom but within the very same space shared with those that pose a threat, Daniel (ibid) refers to this mechanism as a 'home-place' or 'community of resistance' (page 4), in which black people locate themselves to affirm one another and to find a safe space. In my view as a lecturer within a transforming institution, I felt that this could have a negative influence to the spirit of togetherness envisioned in the mission statement of the UFS and therefore needed to be addressed.

\section{Language differences}

Both white and black students pointed to language differences as another main reason why they sat separately in class and did not favour working in groups with those using a different language. However, although this point was raised by both groups, it was raised from different standpoints. On the one hand, the black students felt that Afrikaans as a language of formal communication and instruction was used by their peers to exclude them. On the other hand, the Afrikaans speaking students felt it was their right to use a language that they were comfortable with and one of the official languages used by the UFS, which made it difficult for them to form discussion groups with those that were using English for communication purposes. In this case, elements of marginalisation and problematisation as discussed earlier (Essed, 1991; Harding, 1993) could already be traced, with black students seeing the problem as lying in the white students and the white students protecting their right to use their preferred language on the exclusion of others. This was a problem that needed to be tackled and I went to the planning stage already conscious of the students positions.

Most of the white students with whom I had conversations indicated that they were comfortable in Afrikaans (which most of the non-Afrikaans speakers did not understand) and during group discussions they used the language to communicate. Some of the responses were the following:

You should understand that we understand more if we discuss with people that understand our language. It is not like we have anything against our classmates. But when you discuss, the most natural language is your own language. I hope you understand that...

Ma'am, I hope you are not insinuating that we are being discriminatory. I assure you, that it is not an issue here. We struggle very much in class having to speak English and some of us don't understand that language well. You can't speak Afrikaans either. So, we find it a bit easier to understand the concepts in class if we get a chance to discuss them in Afrikaans. Sitting together at one part of the class, I think is for this purpose. Besides, even you cannot feel comfortable if you are not sitting close to your friend in class. This has nothing to do with race!

Despite the above seemingly sound reasons that students claim contributed to a lack of unity and oneness in class through exclusion; I was still troubled and wanted to improve the situation. The segregated sitting and preference for same race groupings did not open spaces for collaborative work among these students. The group assignments and portfolios that they had to compile needed group effort. Such collaborative work was, in all cases, racially biased. My question was: How as a lecturer I could prepare these students for the realities of diversity, a situation that they were going to meet in school after their training as teachers? 


\section{Planning}

In line with the action research approach of McNiff and Whitehead (2010: 11) and Cresswell (2010: 28), I had to consider a plan that could help address the problem in my class. Since this was an inclusive education class, I decided that I would use the concept of inclusion to reach out to my students through a whole class discussion. In our classes, inclusion is conceptualised as a process in which everybody benefits from a pedagogical process, regardless of differences in abilities, ethnicity, gender and race (Education White Paper 3, 2001). For some time we had discussed inclusion not only in the context of the school, but also how aspects of inclusion could also be applied in our higher education lecture rooms. I decided that I would use this conceptualisation as a point of departure to initiate a discussion on acceptance of the 'other'.

Furthermore, my plan was that if the discussions succeeded in making my students see the need to work together beyond colour and language divisions, I would then give them a group assignment to work on. This assignment would require students to carry out research on what inclusion entailed in racially diverse education contexts. The exercise would still be in line with the content of the course; thus, they would not feel side-tracked by it. My plan was to mix the groups in terms of race. I could not emphasise gender because my class was predominantly female, with the exception of two males.

It should be noted that although some people may view this exercise as one undertaken only by myself as a lecturer without contributions from my class, I believed that it could work in bringing unity to students, if they were not fully aware of the purpose of the exercise. My belief was that if I kept them informed and involved in the planning from the beginning, some would possibly work hard to display the disingenuous unity that I needed while doing the assignments, without the commitment to change their practice. I needed them to first understand the importance of unity and oneness by engaging in discussions and then implementing their understanding by working together in groups. Thereafter, through class discussions, they would be involved in a reflection exercise which would tap into how much they had used the discussions to reflect on their own practices and how much their initial visions had been challenged by the exercises.

\section{Taking action}

My first step in addressing the problems that my students had raised was to give them a group assignment. Generally group assignments are beneficial for students as they help them to work together to accomplish shared goals and to maximise their potential and that of the others (Iteach, 2009: 4). To do the first exercise in my case, the students were divided into groups of three members. To ensure that the groups were racially mixed, I had the students sitting in a circle and picking from a box papers on which I had written the numbers one to three. All the ones, twos, and threes sat together. I should clarify that as students sat in a circle to pick group numbers I asked them to ensure that they were racially mixed to avoid having the same race members in one group. The task involved students visiting two schools within a period of two weeks to observe how teachers addressed the challenges of diversity. The findings from these observations needed to be presented by the groups in class. They also had to make use of the library and research intervention strategies that could assist teachers in schools to handle issues of diversity. The focus of the observations was not on race as the only item of observation, since this was not the purpose of the exercise. However, I 
believed that as these groups collaborated in gathering information about diversity, they would be challenging their own beliefs, attitudes and stereotypes pertaining to diversity.

\section{Presentations}

After two weeks during the presentations in class, I noticed that there were groups that had worked together on the assignment and others that had not worked together. The presentations followed a 15-minute report on the observations and 15 minutes of questions from the whole class. Some groups had not chosen a person to present on their behalf. They all stood in-front of the class and each presented a piece. What I noticed was that this approach was taken by the groups that had not worked through the task as a group, but had opted to allocate small tasks to group members to do for both the observations and the literature search. This was evident in the organisation of the information which affected the coherence of the presentation. In these cases, every member of the group read from what they had prepared and it was difficult for group members to support one another during questions. For example, in one group, a member raised an issue of staff seating arrangements that she had observed in one school which she thought showed a lack of team spirit between black and white teachers. During the questioning session, group members could not substantiate why they thought sitting in separate spaces for the teachers would affect teachers' awareness of diversity. They all looked at the person who raised the issue to respond. After the presentation, I allowed time for the students to reflect on the presentations in general. Reflections are considered an essential part of a collaborative exercise. According to the Literacy and Numeracy Secretariat (2010: 4), setting aside moments for reflection provides opportunities for collective thinking in which students and their teachers can plan their next step of action to improve practice. In our presentations, students themselves had noticed that groups did not get together to discuss, but presented individual work standing in-front of the class in a group.

After this first presentation, the students and I worked together on identifying the reasons why the task was not a success. Some of the reasons that were raised included staying far from one another, other members not willing to sit in a group and reluctance to contribute during group discussions. What I experienced resonates with the view of Balasooriya, Di Corpo and Hawkins (2010: 2, 3), that it was a challenge to manage group dynamics when facilitating collaborative learning. We however agreed that marks should not be allocated for the activity and to give groups time to discuss their experiences during school observations and subsequently present an integrated voice to their observations. The challenges of working together in context where racial tensions had sown divisions were evident in this exercise. These types of challenges have been discussed by Balasooriya, Di Corpo and Hawkins (2010: 2) as emanating from a lack of trust, stereotypes of inferiority and superiority and students who just work better in their own spaces. In addition,, issues of a lack of cohesion, difficult personalities and a lack of motivation were also highlighted as hindering successful collaborative learning among students (Numeracy Secretariat, 2010: 5). These group problems seemed also to play a role in the groups formed and were some of the issues that were raised during our reflection session. Regarding the issue of students staying far from one another, we suggested the use of technology as a communication tool. This included the use of cell phones through SMSs, Facebook, WhatsApp and other social networks, as well as the online teaching and learning platform that the UFS uses, namely BlackBoard. On BlackBoard there was a discussion forum (space) for students and lecturers and it could be an effective tool for discussions. Students could also use these spaces to share the literature that 
they had read in preparing for the presentation. One other suggestion that was raised was to choose one member in each group, who could present the group work. After this reflection and evaluation session, students appeared to be more satisfied and some indicated that they were looking forward to working on the task again.

I should point out that the exercise was also challenging for me as a practitioner striving to improve my own practice. I had to reflect on how damaging it could be to insist that students work in groups, when they show resistance to this practice. My major concern was that I was robbing the Afrikaans students of a chance to use their language when mixing them with non-Afrikaans speakers. This could be regarded by my students as against the UFS dual language policy which clearly stipulates that students have a right to choose the medium of instruction between English and Afrikaans (UFS Language Policy, 2001). The other concern was the exposure that I was giving to my English speaking students, who had clearly indicated that their colleagues were reluctant to engage in English. I had to achieve a balance between encouraging my students to work together and what Balasooriya, Di Corpo and Hawkins (2010:2) believe "actually harm individuals and the learning climate".

While at some point I thought pursuing my goal of bringing unity and togetherness among my students was futile, I decided to continue with the exercise and take the risk of being called to task for disrupting the students' learning.

Before the students could continue with their next round of presentations, I reminded them that the exercise was not meant to compromise any one of them but to create a learning environment in which people could enhance one another's learning. We discussed Vygotsky's social constructivism in stressing the importance of others in a learning environment and emphasised that in working together in the exercise that I had given to them, they were scaffolding one another's learning experiences. I also reminded them that they would be dispatched to schools at the end of their studies, where they would have to work with people from diverse backgrounds. I urged them to view the exercise as a form of practice in preparation for the realities of the schools in which they were to work.

\section{Second phase of presentations}

The second phase of our presentations went much better than the first round. The students came well prepared and the team spirit was apparent from the seating arrangements in class. When I walked into the class, the students were still finishing up their presentations and they were sitting in circles in groups. I did not disturb the continuing discussions as I believed they were serving the purpose for which they were meant: getting students to work together. I allowed an extra fifteen minutes for them to complete the exercise. When the discussions started, they had group representatives to present and some groups had designed power points and posters for their presentations. Much effort had gone into the presentations. I noticed this, for example, from the projections which had citations. Almost all the groups, with the exception of one, related their presentations to their own experiences and the questioning sessions turned into real debates on how the issues of inclusion and diversity related to everybody in class. I was impressed that without accusing one another, students took time in their groups to reflect on how schools were handling issues of diversity and how they created spaces for diversity to thrive.

The challenge that arose however was that the class challenged one another on how inclusive they were themselves and at the end the presentations turned into the UFS case of black and white divisions and how these are also apparent in the school context. I was really worried 
that this could cause divisions in class, since this discussion seemed to take the direction of blaming one another for failure to accommodate diversity. However, I drew direction from the Numeracy Secretariat (2010: 1) that noted that collaborative exercises had to assist students to reflect on their actions and underlying beliefs which had the potential to harm unity within the social context.

During our discussion, the white students claimed that they were always willing to accommodate everybody but their black colleagues seemed to reject them only because they regarded every white person as racist. I became concerned that the discussion would turn into a heated argument on race and that it would spoil the intended outcome. Thus, I intervened by asking the students to focus more on the findings of their exercise and to reflect on the suggested interventions from the literature and their observations as a point of departure to challenge their own dispositions, feeling that this could be a way of helping my students to reflect on themselves. According to Balasooriya (2010: 4), reflecting on oneself during collaborative learning assists in the development of positive group dynamics. Based on this assumption, I encouraged my students that in the next class, which was to be our last class, we would look at our personal reflections on how we could improve our own endeavours to accept difference and diversity and work in unity and togetherness. What made it easy for such discussions to continue in all the contact sessions was that the module was non-examinable, so we could delve into any issue of inclusion without fear that we were not covering the content that would be asked in the examination, while still working within the intended outcomes of the module.

I left the class that day with mixed feelings; satisfied as well as challenged. Since the exercise was meant to enhance the togetherness of students through collaborative projects and exercises, I had to evaluate the success of the exercise. I also interrogated the role that I played in the whole exercise as a course lecturer with the outcomes, as stated in the study guide and as a facilitator of these critical discussions. I also had to reflect on how, in the process of trying to facilitate unity among my students and exposing them to the realities of diversity, I was improving my own practice in terms of showing the same spirit of togetherness and unity in my own class. The debate that my students had during the presentations alerted me to some of the issues that threatened the realisation of the vision and mission of the UFS and the Faculty of Education to function beyond all types of divisions and work in unity. I realised that to facilitate unity, I also had to be open to my students, as well as being conscious of diversity at the UFS.

\section{Reflection and evaluation}

\section{Last phase of presentations (personal reflections)}

The task for this round of discussions was for all of us to choose any issue from our second discussion and indicate how it challenged us to interrogate the way we had been doing things or to indicate how it challenged our thinking. We had to do this by linking our reflections to one of the outcomes of the course which was to enable students to demonstrate insights into the systems of inclusion and exclusion within the South African education context. During the discussions, some students felt that working together in unity and appreciating diversity was threatened by language divides. One student, who was also a staff member at the UFS, said the following about language: 
We never think about how much impact the use of language that is not understood by others influence the perceptions that people formulate about us have. I think if we had a common language we would have dealt with one factor that divide us and then we would have to fewer issues to work on. I feel that I have to show that I appreciate others and want to accommodate them by speaking the language that they understand.

The majority of the class understood the need to accommodate others by using a common language. This took us to our next point, which was sitting separately in class. Luckily, this was one of their own observations during school visits that white and black staff members, in most of the schools they visited, did not sit together during short and long break and that this led to the staff members not understanding one another's background, which in turn, was a threat to unity. The students promised that they would sit next to the person of the other race in all classes as a way of getting to understand the 'other'. We all wished that the class we had had that day was not the last class, otherwise we would start implementing our suggestions in our own class.

One other issue that came up in the reflections involved students' awareness during their school visits that schools in general are diverse, ranging from disability to class and race. The students had noticed how challenging it was for teachers to adapt to this diversity and to handle students from diverse backgrounds. They realised how important it was for teachers in schools to get to understand their learners and colleagues to create healthy learning environments. The group became excited as they brainstormed ways in which such diversity could be handled. Some of their suggestions were:

- Teachers understanding of the learners' cultural background;

- Teachers being sensitive to diversity and treating each learner as an individual with the potential to succeed;

- Teachers regarding all learners as valuable and having the potential to succeed; and

- Teachers should understand that learners are different but may all come with knowledge that could contribute positively to the learning experience.

These points were then used to reflect on our own behaviour when dealing with others and we all felt that there is always room for improvement. The class ended with all students willing to improve on their view of others.

\section{Discussion}

The classroom practice that my class and I engaged in, shows that there is a possibility that if staff and teachers put effort into creating socially sustainable learning environments, there could be success. Although, through the demanding exercise that my students and I engaged in, it could be noticed that elements of marginalisation and problematisation got exposed in all of us, through the collaborative exercise that we engaged in as a class our behaviours were challenged and we found a space to get to understand one another. It has surfaced as is reported in this paper that students almost turned the exercise into a race war, almost failing to take accountability for their own actions, but blaming the 'other' and justifying their exclusions of each other. What made this exercise successful was that these students moved 
from their positions of marginalisation and problematisation. Although, at the beginning, the students defaulted on stereotypical thinking about each other as black and white, through the exercise in which they immersed themselves, they improved on their negative beliefs, attitudes and approaches towards one another. This seemed to be in harmony with the belief of some of the learning experts, who also consider collaborative reflective exercises as a way of scaffolding learners' academic and social experiences (Balasooriya, Di Corpo and Hawkins, 2010: 1; Numeracy Secretariat, 2010: 4).

The problems that the students raised at the beginning of this action research exercise had at first seemed insurmountable. Both groups of black and white learners seemed to have believed that it was impossible for them to work together as a unit and to understand that every single one of them could bring to the learning experience some knowledge capital that could benefit everybody else. After the collaborative exercise, they began to see the potential in one another. The stereotypes that they had held about each other at the beginning had been dealt with successfully. The success could be seen in the reflections that they had had in class. Although it cannot be claimed that the students totally moved beyond their differences, they at least had gone through a self-reflective exercise that influenced them to interrogate their view of diversity. The importance of reflective practices within the education context is emphasised by Bolton (2009: 4) who strongly believes that reflections pave the way for students to engage in challenging questions. These questions that are mainly directed at oneself should not only be descriptive about one but should also challenge the "political and social structures" that shape a person (page 25). As such, important points during a collaborative reflective exercise could be:

- What you can change in your context; how to work with what you cannot;

- How to value the perspective of others, however different they are to you;

- How others perceive you, and their feelings and thoughts about events;

- Why you become stressed, and its impact on life and practice; and

- How to counteract seemingly given social, cultural and political structures.

(Bolton, 2009: 4)

It is in view of this that I believe that at the end my students were sensitised towards transformation and their initial beliefs and dispositions positively changed, because they challenged themselves by reflecting on the abovementioned points.

\section{Conclusion}

The vision of the UFS is to be a university "recognised across the world for excellence in academic achievement and in human reconciliation" 3 . Drawing from this institutional vision, the Faculty of Education also strives to affirm "the dignity of its students, its staff and the community with which it engages, and draws on their diversity as a source of strength." ${ }^{4}$

3 http://www.ufs.ac.za/content.aspx?id=12

4 http://edu.ufs.ac.za/content.aspx?id=14

TD, 9(3), Spec. ed, December 2013, pp. 430-445. 
This commitment to create spaces that are welcoming for all (cf. Milem et al., 2005) is declared in the UFS Mission Statement to demonstrate "in everyday practice the value of human togetherness and solidarity across social and historical divides". This paper reported on a challenge that I set myself, in line with the Vision and Mission of the institution and of the Faculty of Education to change my own classroom practice and that of my students to create an atmosphere of unity in an environment where students can thrive and meaningful learning can take place.

Through the process of action research, I believe this project has contributed to the intended outcome of togetherness, even if only on a small scale. My students and I were limited in terms of time; nevertheless, I believe that I should try to build on this by continuing to engage my students in similar exercises and to work collaboratively with all lecturers on the programme towards sustainability.

\section{Bibliography}

Balasooriya, C, Di Corpo, S and Hawkins, N. 2010. 'The facilitation of collaborative learning: what works?' Higher Education Management and Policy. 22(2). http://dx.doi.org/10.1787/hemp-22-5kmd4hqzhwvh. Accessed: 15 October 2013

Bunting, I. 2006. The higher education landscape under apartheid. Higher Education Dynamics. 10 (1): 35-52.

Carrim, N. 1998. Anti-racism and the 'New' South African Educational Order. Journal of Education. 3(28).

Cresswell, J. \& Clark P. 2008. Designing and Conducting Mixed Method Research. London: Sage.

Daniel, J. 2009. 'African American women's journey to academia and their experiences as occupational therapy professors.' McNair Scholars' Research Journal. 2(1): 49-66.

DOE. 2001. Special Needs Education: Building an Inclusive Education and Training. Pretoria: DOE.

DoE (Department of Education). 2008. Report of the Ministerial Committee on Transformation and Social Cohesion and the Elimination of Discrimination in Public Higher Education Institutions. Pretoria: DOE.

Eagle, G., Hayes, G., \& Sibanda, T. 2006. Standpoint Methodologies. In: Terre Blanche, M., Durrheim, K. \& Painter, D (Eds). Research in Practice. Cape Town: CUP.

Essed, P. 1991. Everyday Racism. In Essed, P (ed). Understanding everyday racism: an Interdisciplinary Theory. Newbury Park CA: Sage.

Given, L. 2008. The Sage Encyclopaedia of Qualitative Research Methods. London: Sage.

Hall, A. 2007. 'Vygotsky Goes Online: Learning Design from a Socio-cultural Perspective.' Learning and Socio-cultural Theory: Exploring Modern Vygotskian Perspectives International Workshop 2007. 1(1): 94-107.

Harding, S. 1993. Rethinking Standpoint Epistemology: What is 'Strong Objectivity'. In Alcoff, L \& Potter, E (eds). Feminist Epistemologies. London: Routledge. 
Hrabowski, D. 2011. Institutional Change in Higher Education: Innovation and Collabroration. A Policy Paper: Mcraw-Hill.

Kawulich, B. 2005. 'Participant observation as a data collection method.' Forum Qualitative Sozialforschung / Forum: Qualitative Social Research. 6(2). http://nbnresolving.de/urn:nbn:de:0114-fqs0502430. Accessed: 15 October 2013

Literacy and Numeracy Secretariat. 2010. 'Collaborative teacher inquiry.' The Capacity Building Series (Special Edition). (16): 1-8.

Mabokela, O \& Wei, N. 2007. 'Lingering effects of the past on a university merger process in post-apartheid South Africa.' International Education Journal. 160-171.

McNiff, J. 2010. Action Research for Professional Development: Concise Advice for New Action Research. London: Sage.

Milem, J., Chang, M. \& Antonio, A. 2005. Making Diversity Work on Campus: A Research-based Perspective. USA: Association American Colleges and Universities.

Ramohai, J. 2013. A Living Journey towards Understanding Black Woman Academics' Perceptions of Social Transformation in South African Higher Education. Unpublished $\mathrm{PhD}$ Thesis.

Tatum, D. 2003. Why are all Black Kids sitting Together in the Cafeteria? USA: Basicbooks.

UFS. 2003. Language Policy. Bloemfontein: UFS.

Waghid, Y. 2002. 'Knowledge production and higher education transformation in South Africa: Towards reflexivity in university teaching, research and community service.' Higher Education. 43(4): 457 - 488. 